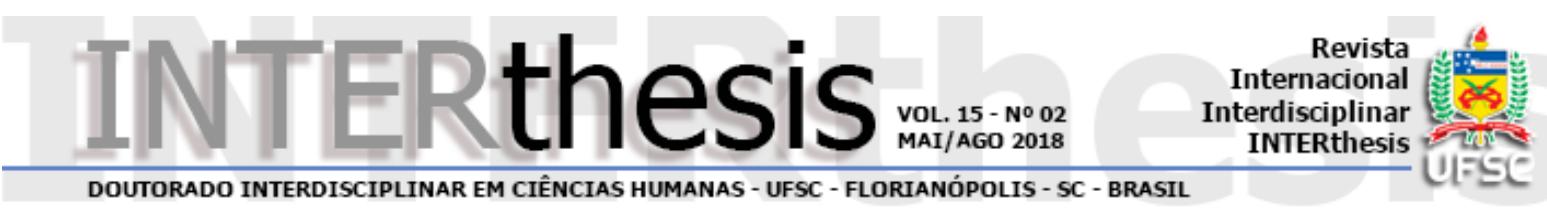

\title{
IMPORTÂNCIA DO UPCYCLING NO DESENVOLVIMENTO DA MODA: ESTUDO DE CASO DA MARCA RECOLLECTION LAB
}

Tamires Joaquim Lucietti ${ }^{1}$ Andréa Cristina Trierweiller ${ }^{2}$ Malena de Souza Ramos ${ }^{3}$ Rafaela Bett Soratto 4

\section{Resumo}

O curto ciclo de vida de um produto da moda tem se mostrado como um grande problema ambiental. Da matéria-prima até o descarte, diversos impactos ambientais são gerados e, como alternativa de minimização, surgem marcas com o conceito de upcycling. Aquilo que teria como destino o lixo, transforma-se em produto com novo apelo e posicionamento no mercado. Este artigo tem como objetivo investigar como a marca Recollection Lab., de Criciúma, Santa Catarina, Brasil reutiliza peças que teriam como fim o descarte, servindo como matéria-prima para o surgimento de um novo nicho no segmento da moda: o upcycling, dando uma nova vida ao produto.

Palavras-chave: Moda. Sustentabilidade. Upcycling. Consumo Consciente.

\section{INTRODUÇÃO}

Um dos grandes desafios do segmento de moda é a inserção do negócio nos preceitos da sustentabilidade, em todos os seus processos produtivos e, além disso, manter-se no mercado atendendo aos desejos dos consumidores que, mesmo prezando pela qualidade e preço, estão cada vez mais exigentes procurando mudanças na vida, optando por modelos produtivos que reduzem os impactos ambientais.

Krucken (2009) defende a ideia de que as mudanças não devem ser bruscas, pois é necessário transformar não só a esfera tecnológica, mas principalmente, a

\footnotetext{
1 Mestranda em Tecnologias da Informação e Comunicação pela Universidade Federal de Santa Catarina. Vinculada ao grupo de pesquisa Gestão da Inovação e Sustentabilidade junto à esta instituição, Florianópolis, SC, Brasil. E-mail: taah.aru@gmail.com

2 Doutora em Engenharia de Produção pela Universidade Federal de Santa Catarina. Professora e Coordenadora do Programa de Pós-Graduação em Tecnologias da Informação e Comunicação e nos cursos de graduação em Tecnologia da Informação e Comunicação, Engenharia da Computação e Engenharia de Energia no Campus de Araranguá da Universidade Federal de Santa Catarina, Araranguá, SC, Brasil E-mail: andreatri@gmail.com

${ }^{3}$ Graduanda em Tecnologias da Informação e Comunicação na Universidade Federal de Santa Catarina, Florianópolis, SC, Brasil. E-mail: malenaaramos@gmail.com

${ }^{4}$ Mestranda em Tecnologias da Informação e Comunicação na Universidade Federal de Santa Catarina. Professora dos cursos Tecnologia em Design de Moda e Técnico em Produção de Moda no Instituto Federal de Educação, Ciência e Tecnologia de Santa Catarina, Campus Araranguá, SC, Brasil. E-mail: rafaelasoratto@gmail.com
} 
social, mais precisamente nos comportamentos, hábitos e modos de viver dos indivíduos.

Nas últimas décadas do século $X X$, originou-se uma tendência mundial para o desenvolvimento de materiais ecológicos, segundo Berlim (2012) além do aspecto ambiental do produto, questões sociais, econômicas, culturais e políticas são analisadas desde o seu processo produtivo até o consumo e posterior descarte. A partir de 1990, tornou-se perceptível a movimentação da indústria da moda em aderir a sustentabilidade como estratégia de diferenciação. Algumas iniciativas que buscaram associar moda e sustentabilidade denominam-se como "moda ética", "moda consciente", "moda verde", "ecofashion", "ecomoda", "green fashion" e "ethical clothing" são expressões comuns no universo da moda que traduzem a relação do segmento com o conceito de sustentabilidade (GALLELI et al, 2016).

Abordando a questão das tendências, resumidamente, pode-se colocar dois marcos: as gerações nascidas a partir dos anos 1980, que cresceram consumindo roupas produzidas, no geral, em condições questionáveis, ou seja, a moda apenas com considerando tendência de rapidez e consumo, com o estar ou não estar na moda. Seguindo esta mentalidade, o descarte parece estar desvinculado do consumo e da moda (BERLIM, 2016). O responsável pelos impactos ambientais é outrem, uma terceira pessoa ou mesmo, uma entidade, excluindo o comprometimento e o dano que cada consumidor provoca, em menor ou maior escala. Afinal, como menciona Braga et al (2003, p. 10): "O responsável pelos problemas ambientais, chamados de "agressões à natureza", é sempre o Homem, um ser genérico, sem nome ou sobrenome, que ninguém conhece e que nunca é punido pelo dano que provoca". Ou ainda, conforme Berlim (2016), essa geração parece perceber a moda como luxo, ligando-a a desfiles, muitas vezes, com coleções desconexas com a realidade, que servem apenas para as passarelas.

Um segundo marco é a percepção da moda como um fenômeno misterioso e instigante, que expressa todos os tempos, é esta efemeridade que a faz ser, atualmente, percebida como uma unidade inseparável de negócio, consumo e mídia, expressando a complexidade atual, oriunda do fenômeno da globalização e das redes digitais (BERLIM, 2016).

Neste cenário, o aumento da produção e do consumo vem refletido nas desigualdades sociais, econômicas e ambientais. A intensidade destas produções, baseadas no modelo capitalista, além de não contribuir para o crescimento 
sustentável, ocasiona pobreza e degradação do meio ambiente. De acordo com Ljungberg (2007), a seleção de materiais sustentáveis implica em mudanças culturais e no estilo de vida dos consumidores. Diante disto, ocasiona preocupação com o futuro do planeta, estimulando a prática de novas ideias, a fim de minimizar os problemas ambientas, surgindo então, o termo upcycling.

Em uma visão otimista, Manzini (2008) destaca que, essas demandas exigiriam novas estruturas sociais, mais flexíveis e sustentáveis, apresentando soluções criativas e mudanças de comportamento. Nestas novas estruturas haveria mais tolerância, empreendedorismo, bens comuns e um ritmo de vida mais lento, com a valorização da tradição, o respeito às estações climáticas e ao espaço local.

\section{SUSTENTABILIDADE}

Segundo Viegas et al. (2015, p. 3), "o conceito de sustentabilidade explora as relações entre desenvolvimento econômico, qualidade ambiental e equidade social". Começou a ser delineado em 1972, na conferência das Nações Unidas sobre Meio Ambiente Humano, em Estocolmo (Suécia) promovido pela ONU (Organização das Nações Unidas). O termo teve origem ao longo da década de 1980, através da conscientização crescente, em que os países necessitam descobrir meios de promover o crescimento de suas economias, todavia sem causar danos ao meio ambiente ou prejudicar o bem-estar das próximas gerações (SAVITZ; WEBER, 2007).

Oliveira et al. (2012), afirma que sustentabilidade é um conceito sistêmico que envolve aspectos econômicos, ambientais, culturais e sociais, afim de alcançar o desenvolvimento sustentável. Deste modo, Elkington (2004) expõe a necessidade de uma visão mais estratégica, com base em três fundamentos essenciais ao desenvolvimento sustentável, conforme a Figura 1. 
Figura 1 - Os três pilares da sustentabilidade

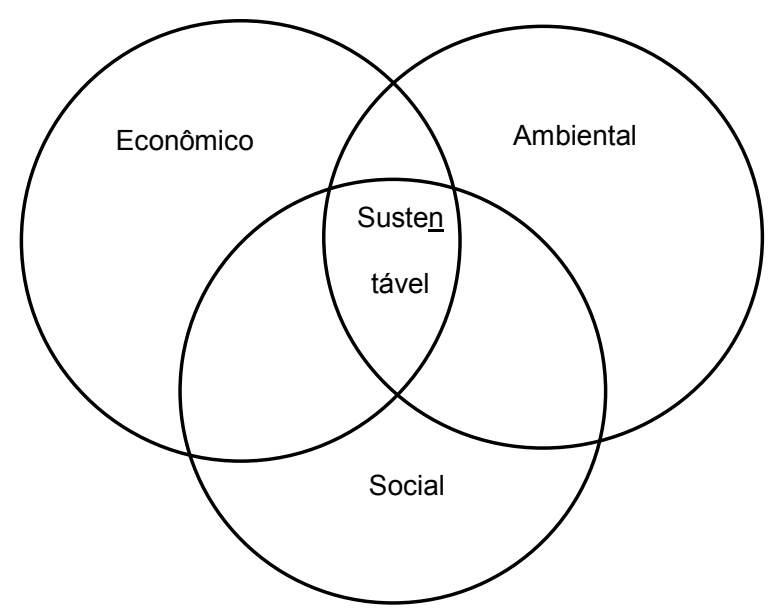

Fonte: Adaptado de Elkington (2004).

A Figura 1 coloca os pilares do conceito de sustentabilidade, infere-se que há uma intersecção virtuosa, ao se aliar as preocupações não apenas com o crescimento econômico (lucro pelo lucro), mas considerando as questões ambientais e sociais em todo o ciclo de vida do produto, ou seja, extração da matéria-prima, manufatura e consumo. Aktas et al. (2013) complementam que para potencializar o valor da empresa esses três elementos do desenvolvimento sustentável devem ser desempenhados para poder ser criado valor sustentável dentro da organização.

Diante disto, Nilipour e Nilipour (2001) afirmam que, o compromisso com as questões sustentáveis tornou-se estratégia importantíssima no cenário competitivo atual. Nesse sentido, a gestão ambiental é uma das principais ferramentas de manutenção, que tem como intuito gerir os recursos naturais, de maneira ecologicamente correta e consciente.

\section{A SUSTENTABILIDADE NA MODA}

No cenário mundial, a indústria da moda tem sido considerada como a terceira atividade econômica em termos de geração de renda e movimentações financeiras. Por outro lado, esta posição de destaque não está alinhada à responsabilidade com o meio ambiente. Pode parecer contraditório tentar unir moda à sustentabilidade considerando que: "o consumo exagerado de roupas e acessórios, bem como a lógica da fast fashion fazem com que a data de validade desses produtos seja curta e nossas relações com eles superficiais" (BERLIM, 2012, p.13). Além da rapidez do mercado da moda, o trabalho escravo ou em condições ilegais conhecido como sweet shops 
apresenta a faceta desumana desta indústria, em que indivíduos estão submetidos a condições precárias de trabalho, a fim de alimentar o setor na produção dos anseios e das necessidades desenfreadas dos consumidores (BERLIM, 2012).

Segundo Fletcher et al. (2011, p. 5) há três assuntos, hoje, que devem ser discutidos e com grande impacto: combustível (energia), alimento e moda. Os dois primeiros são muito estudados; já, a moda, deveria mostrar o imperativo moral de mudar cada aspecto da produção. Ou seja:

A moda é frágil no sentido de que pequenos choques podem levar a grandes alterações, assim, ela muda sucessiva e constantemente, possuindo curtos ciclos de vida, cujos estágios principais são: introdução, emulação, conformidade em massa e declínio (CORNEO et al., 1994).

Devido à pouca durabilidade dos materiais com que são produzidas, as roupas e os modos de vestir mudam com muita frequência. Barthes (1979) afirma que, a moda tem como base alguns grupos de produtores, que buscam a antecipação e a renovação do vestuário. Por outro lado, há uma linha de produtores e consumidores mais conscientes, propensos não somente a comprar em quantidade e pelo menor preço, mas que buscam uma moda mais próxima dos preceitos da sustentabilidade, o que se denomina como slow fashion (moda lenta).

Durante a Primeira Guerra Mundial, a maioria das roupas era consertada ou adaptada para outros membros da família, ou ainda, reutilizadas para serem usadas dentro de caso, como trapos ou colchas de retalhos. Durante a guerra, os fabricantes de roupas reduziram as variedades, tamanhos e cores de suas produções e até mesmo, estimularam os estilistas a criar estilos que usassem menos tecido, evitando adornos desnecessários. No entanto, o espírito de conservação não durou muito; em meados da década de 1920, o consumismo estava de volta. A industrialização cresceu no século $X X$, fornecendo os meios para aumentar a produção. Durante a Segunda Guerra Mundial, a produção e o consumo de muitos bens domésticos, incluindo roupas, cresceram de 10 a $15 \%$ mesmo no meio da guerra e continuam a se expandir até hoje.

A industrialização trouxe o consumismo como parte integrante da economia. $O$ crescimento econômico passou a depender da comercialização contínua de novos produtos e do descarte de produtos antigos simplesmente porque os padrões de estilo promovem sua obsolescência. No entanto, a jornada de uma peça de roupa nem sempre termina no aterro, sendo uma parte reciclada, principalmente de três maneiras: (1) a roupa pode ser exportada a granel, para venda em países em 
desenvolvimento, (2) pode ser - química ou mecanicamente, reciclada - tornando-se material para fabricação de outros produtos, (3) revendida pelo consumidor primário para outros consumidores, a um preço mais baixo; meio facilitado pela Internet. Pois, muitas pessoas vendem diretamente para outras através das redes sociais. Outra saída, cada vez mais popular, é a consignação e brechós.

A produção em massa é mantida pelo movimento fast fashion (moda rápida), definido por Bianchi et al. (2010) como varejistas que lançam vestuários modernos e inovadores para os consumidores a cada duas ou três semanas a preços baixos e com curto ciclo de vida, aumentando as vendas através da compra por impulso e sendo rotulados como moda descartável. Diante desta compra impulsiva, muitas vezes, a opção de descarte, "jogar no lixo", acaba sendo a mais praticada pelos consumidores do fast fashion, para se livrar das peças que não são mais necessárias ou que estejam fora das tendências. Assim, este crescente volume de resíduos têxteis, tornou-se uma questão ambiental.

Em contrapartida, o slow fashion surge como um movimento, que promove a cultura do slow, estilos de vida mais lentos e, portanto, mais saudáveis e sustentáveis. O slow fashion é mais do que a redução da velocidade de produção, representa uma nova forma de ver o mundo, em que há uma ruptura com as práticas atuais do setor com os valores do fast fashion (FLETCHER et al., 2011). O movimento slow fashion propõe uma reflexão tanto no lado da oferta quanto do consumo de bens, ou seja, é uma tendência para a desaceleração do tempo de produção e consumo; além disso, para o empoderamento e ativismo político na área do design de moda (BERLIM, 2016).

Assim, junto ao movimento slow fashion, um estilo que vem chamando a atenção é o upcycling (FLETCHER et al., 2011). As marcas que trabalham com o slow fashion buscam questões de inspiração mais profundas na sociedade, para reconhecer as micro tendências de comportamento, que geralmente são as que geram as macro tendências e se revelam em redes de fast fashion. Já, o slow fashion incentiva o reconhecimento de que os impactos das escolhas, principalmente de consumo, afetam o ambiente e as pessoas, como as decisões dos produtores, designers, fabricantes e varejistas, todos interligados ao sistema ambiental e social (SAFFI, 2015). Sendo assim, quanto ao consumo na moda, torna-se importante destacar que: 
Na sociedade pós-industrial, assistimos à extensão da lógica da moda — isto é, o lançamento permanente de novos produtos, tornando os anteriores automaticamente obsoletos - aos principais setores de produção de bens de consumo e de bens culturais. Afinal, do ponto de vista econômico, o "carro do ano" vem cumprir a mesma função da "nova coleção" de roupas da marca "X" ou da "grande novidade" da indústria fonográfica — ou seja, alimentar o consumo.... Por outro lado, é cada vez mais frequente a redundância (a repetição) das mesmas tendências estéticas em produtos oriundos de setores industriais diferentes. É marcante, por exemplo, a coincidência de elementos, como cores e formas, em roupas e em carros: é o caso do verde maçã, onipresente nas vitrinas do verão 97 , a cor escolhida para promover o lançamento do automóvel Pálio. Do mesmo modo, o catálogo verão 97 da Habitat, marca francesa de design, utilizava insistentemente as cores mais vistas nas vitrinas de roupas (verde, laranja, azul turquesa) (CALDAS, 2017).

Grande parte dos produtos causam, de alguma forma, impactos ambientais durante o seu ciclo de vida, desde a extração da matéria-prima, produção e uso até a gestão e disposição dos resíduos. Esses efeitos ambientais acontecem por várias decisões inter-relacionadas, nos estágios do ciclo de vida do produto, desde as fases de pré-produção, produção, distribuição, uso, descarte, até sua reutilização ou reciclagem (MALAGUTI, 2005).

O Processo de Desenvolvimento de Produto (PDP) consiste em um conjunto de atividades que, a partir das necessidades do mercado e das capacidades tecnológicas, procura chegar às especificações de um produto e de seu processo de produção, envolve atividades de lançamento, acompanhamento e descontinuidade do produto no mercado. O PDP pode ser dividido nas macrofases de Pré-Desenvolvimento, Desenvolvimento e a de PósDesenvolvimento (ROZENFELD et al., 2006).

Baumann et al. (2002), afirmam que, durante o ciclo de vida de um produto, seja na extração da matéria-prima, produção e uso até a gestão e disposição dos resíduos, acabam de certa forma ocasionado impactos ambientais.

As decisões tomadas nos estágios do ciclo de vida do produto estão interrelacionadas aos resultados causados ao meio ambiente. O ciclo de vida de um produto passa por diversas etapas, desde sua concepção até o destino desejado. A Figura 2 mostra a divisão das três macro fases que são: pré, desenvolvimento e pós do ciclo do produto, bem como suas etapas:

Figura 2 - Ciclo de vida do produto.

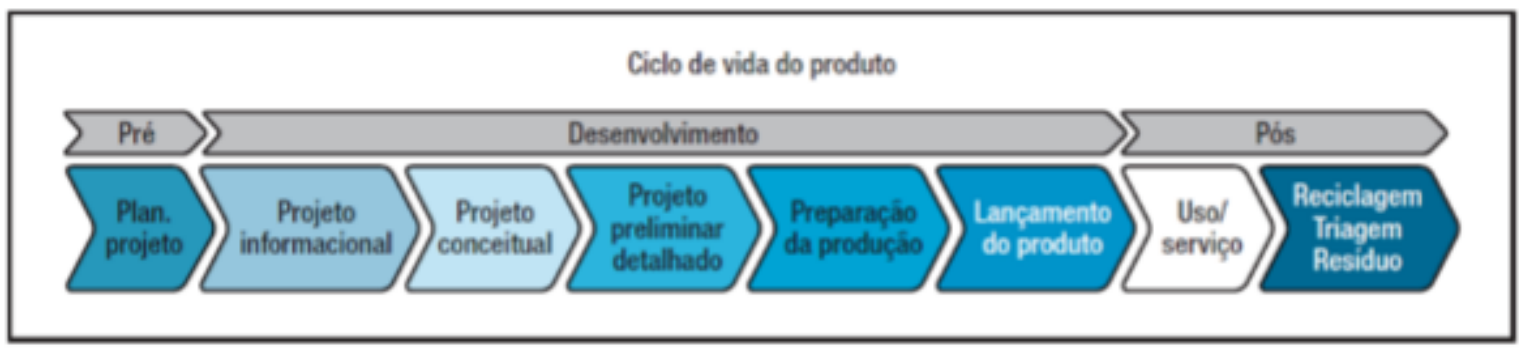

Fonte: Rozenfeld et al. (2006). 
O objetivo do pré-desenvolvimento é avaliar oportunidades e demandas do mercado. Na etapa do desenvolvimento, estão atividades relativas à avaliação do produto em desenvolvimento, inicia-se com o teste de conceito, o teste de protótipos e o teste de lote piloto. No Pós-desenvolvimento, o processo de reciclagem e resíduos são de extrema relevância na logística reversa (ROZENFELD et al., 2006).

Atualmente, muitas empresas vêm se preocupando com o desenvolvimento sustentável e procuram formas de contribuir para o futuro do planeta, visando minimizar os problemas ambientais. No segmento da moda, uma iniciativa crescente é o upcycling, um processo de recuperação, que utiliza materiais que já seriam descartados, transformando-os em novos produtos com melhor qualidade e valor ambiental, sem passar por qualquer tipo de processo químico. O upcycling ou upcycled vem se destacando no âmbito das discussões sobre reciclagem e meio ambiente (SHOUP, 2008).

O termo upcycling foi usado por William McDonough e Michael Braungart em seu livro, Cradle to Cradle: Remaking the Way We Make Things, de 2002. Eles afirmam que o objetivo deste movimento é evitar o descarte de materiais úteis. Reduzindo o consumo de novas matérias-primas durante a criação de novos produtos, o que pode resultar em redução do consumo de energia, poluição do ar e da água e até, das emissões de gases de efeito estufa.

Segundo Saffi (2015), o upcycling vem crescendo significativamente isso porque, além de ser ecologicamente correto, o custo é bastante reduzido, colocandoo em posição de destaque no mercado e sendo a opção preferida de artesãos adeptos da reutilização. Dessa forma, o upcycling está cada vez mais presente, não somente no design de moda, mas também, na decoração e em outras áreas. Um exemplo bem conhecido é a utilização de lona de caminhões para a fabricação de roupas, bolsas, chapéus (Figura 3).

Figura 3 - Produtos desenvolvidos com lona de caminhão.

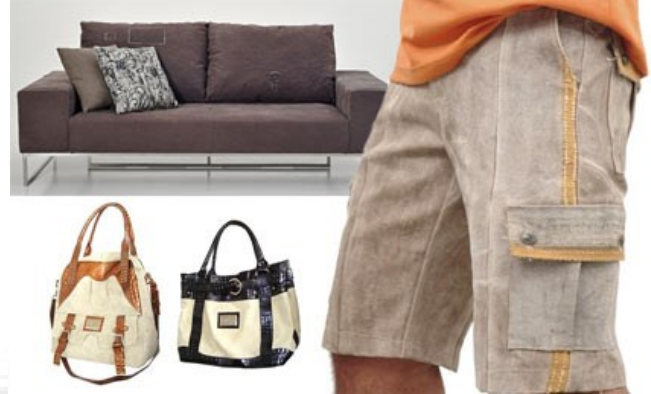

Fonte: Adaptado do website <http://www.ecodesenvolvimento.org/posts/2011/junho/shopping-ecodupcycling-com-lona-de-caminhao >. 
As vantagens da aplicação do upcycling na indústria, segundo Aus (2011) consistem em:

- Na facilidade de implantação dos processos de design e na rapidez que o designer se envolve para a criação de produtos de valor acrescentado;

- Na possibilidade de resolução de problemas dentro da indústria, sem que seja necessário recorrer à gestão dos resíduos;

- Na minimização do uso de recursos energéticos;

- Na capacidade de reduzir ou até mesmo eliminar, a produção de resíduos;

- Na valorização dos materiais já existentes;

- Na criação do "novo" produto único através do "antigo", no interior da produção massificada;

- Na oportunidade de seleção do melhor processo a aplicação através da perspectiva ambiental e na perspectiva sócio ética.

Outras iniciativas que vem ganhando importância são recycling, que é a reciclagem, e o downcycling, que é o processo de recuperação de um material para ser reutilizado em um produto com valor inferior, comprometendo a integridade do material. A reciclagem é na verdade um downcycling, pois reduz a qualidade do material ao longo do tempo, neste processo (MCDONOUGH et al., 2002; FUADLUKE, 2010); conforme se observa na Figura 4.

Figura 4 - Símbolo e exemplos de Recycling, Downcycling e Upcycling

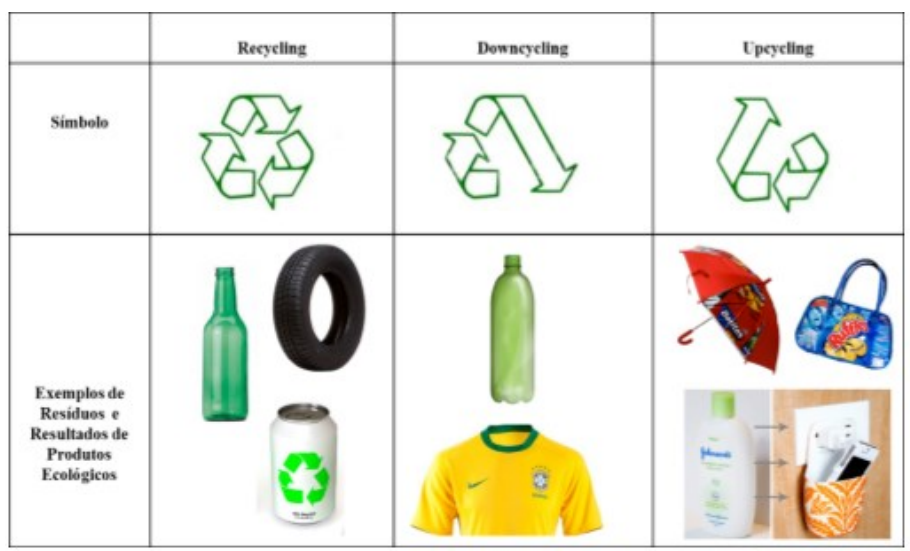

Fonte: Adaptado de Moreira et al. (2017).

Assim, ao desenvolver e criar um produto, inúmeras empresas têm o cuidado de aplicar os 3 Rs (Reduzir, Reutilizar e Reciclar), com o intuito de diminuir o prejuízo ao meio ambiente. A Redução busca a diminuição na fonte; ou seja, por meio de redução de resíduos acarretados pela fabricação e consumo de produtos, conforme 
definição da Environment Protection Agency (EPA, 2017). A Reutilização de produtos ou parte deles, que muitas vezes poderiam ser considerados inúteis, atribui uma nova função ou aplicação. Quanto à reciclagem, recupera-se a matéria-prima constituinte dos produtos com o propósito de desenvolvimento e produção de novos produtos.

De acordo com Moreira et al. (2015), os processos recycling, downcycling e upcycling têm relevância na diminuição dos impactos ao meio ambiente e são procedimentos que devem ser considerados pelas organizações, já que influenciam novas oportunidades de lucro, com matéria-prima, que seria previamente descartada.

O processo upcycling compreende a percepção de valor em todos os produtos potencialmente descartáveis, de forma a minimizar possíveis impactos negativos ao meio ambiente, por não utilizar energia e produtos químicos como acontece no Downcycling. O material, uma embalagem de biscoito, por exemplo, poderia ser descartada no meio ambiente, sem passar por processos físicos e químicos, podem-se transformar em guarda-chuvas, bolsas e diversos outros produtos de valor. Para tanto, observa-se a necessidade de criatividade agregada ao processo e, principalmente, de tecnologia que configure um processo inovativo (MOREIRA et al., 2015, p. 7).

O princípio é a utilização de materiais ou produtos, que se encontram no fim da vida útil, da mesma forma em que foram encontrados no lixo, para que adquiram novas funções. Desta forma, evita-se o desperdício de materiais potencialmente úteis e, também, possibilita-se a redução dos excedentes provenientes dos processos industriais (ANICET, 2012, p. 102).

\section{PROCEDIMENTOS METODOLÓGICOS}

Essa pesquisa tem natureza qualitativa, descritiva e exploratória, na qual foi realizada uma entrevista com a designer Larissa Moraes, da marca Recollection Lab de Criciúma-SC. Trata-se de um estudo de caso, que permite o conhecimento, por meio de uma análise profunda, dos objetos na reformulação de problemas e na construção de hipóteses (RAUEN, 2002).

Construiu-se um roteiro de entrevista com perguntas, previamente elaboradas; sendo que, a entrevista foi realizada via vídeo conferência. Diante deste contexto, o artigo tem como objetivo investigar como a marca Recollection Lab., da cidade de Criciúma - Santa Catarina, Brasil utiliza o upcycling como seu principal meio produtivo. No atelier, o desenvolvimento das peças de moda, são customizadas e/ou transformadas, baseando-se no conceito de upcycling, como principal meio produtivo. 


\section{ESTUDO DE CASO - MARCA RECOLLECTION LAB}

No início da entrevista, questionou-se sobre o tempo em que a proprietária Larissa Moraes, do atelier Recollection Lab atua com transformações e customizações de roupas e qual o objetivo da empresa. A designer respondeu: "O Recollection Lab começou com meu projeto de TCC - Trabalho de Conclusão do Curso de Artes Visuais, da Universidade do Extremo Sul Catarinense - UNESC, em junho de 2012. Porém, saiu mesmo do papel, um ano depois, em 2013. Nesse ano, passei a cortar calças jeans masculinas, transformando-as em shorts, mais que uma atitude econômica, passou a ser um produto, com novo apelo e assim, em setembro de 2014, saí do quarto improvisado, onde trabalhava, para o atelier. Na sequência, passei a customizar/consertar bolsas, sapatos, casacos de couro e de pele e tudo aquilo que minhas clientes quisessem, de maneira criativa. Assim, hoje, o objetivo do Recollection Lab é continuar esse serviço exclusivo, que estimula a sustentabilidade, originalidade e também, a memória das peças que trabalhamos."

$\mathrm{Na}$ questão 2, em relação aos motivos que levaram a criar a marca, que tem como seu principal meio de produção, o estilo upcycling, a entrevistada enfatizou: "Senti vontade de fazer uma moda diferente, sem amarrações nas tendências padronizadas pelo mercado convencional, e sim, uma moda voltada às recordações - que é o significado da palavra Recollection - das clientes".

Ao ser questionada se trabalha sozinha ou em equipe, a entrevistada colocou que, mantém uma equipe composta por três pessoas e que, a forma de contratação dos terceiros se dá como "autônomo, com empresa registrada".

Dentre os elementos citados na questão 6 , como importantes para a inspiração no momento de criar, a entrevistada destacou: a) Referências de Moda (por meio das tendências de moda); b) Influências Culturais (por meio da diversidade cultural como: artesanato, paisagem, arte, música, dança, gastronomia e etc); c) Influências Históricas (por meio da história local, regional e nacional bem como lendas e contos); d) Influências Tecnológicas (por meio das últimas tecnologias lançadas no mercado, utilizando materiais recém lançados); e) Influências Pessoais (por meio de lembranças, gosto, escolhas pessoais).

Ao ser questionada sobre a fonte de pesquisa de referências para a criação das suas customizações, a entrevistada destacou: a) Revistas de Moda; b) Jornais e revistas customizadas; c) Internet por meio de buscas como o Google; d) Redes 
sociais como Facebook, Instagram, SnapChat; e) Redes sociais voltados à moda como o Pinterest; f) Nas ruas e nas vitrines; g) Nos brechós físicos e/ou virtuais.

Quanto ao público-alvo da empresa, a entrevistada relatou que são "pessoas interessadas em moda original e sustentável, que valorizam o antigo, o usado, o trabalho manual. Um público abrangente, tanto na faixa etária como no gênero.

Sobre o valor médio cobrado por peça, o objetivo era saber se os valores são acessíveis, considerando a exclusividade agregada ao produto. A artista respondeu que, de acordo com o público, os preços variam muito. Ou seja, desde $R \$ 40,00$ para um desgaste no jeans até $R \$ 500,00$ por peças com customizações mais sofisticadas. Na Figura 5, estão peças exclusivas, desenvolvidas pela marca.

Figura 5 - Marca Recollection Lab.

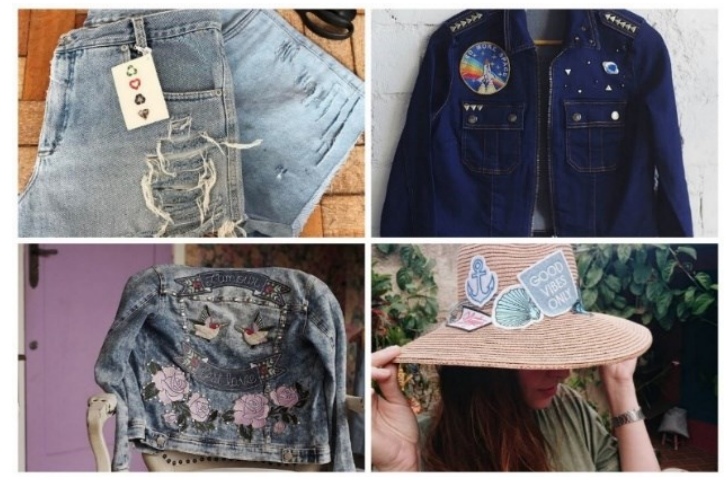

Fonte: www.instagram.com/recollectionlab

Quanto aos motivos que a levaram a realizar este tipo de trabalho, destacou: a) reconhecimento; b) valor econômico; c) sustentabilidade e d) inclusão social.

Enfim, uma curiosidade é que a artista, proprietária e fundadora da marca em estudo, por desenvolver trabalhos de transformação e customização de roupas, também reaproveita armarinhos e sobras de tecidos, como segue: "tenho uma série de coisas [...], desde ferragens de bolsas antigas, botões, tecido até peças de roupas descartadas por defeitos”. E ainda, a marca faz controle de fornecedores, que obedecem a critérios ambientais, além de procurar fornecedores locais.

Quanto à divulgação da marca, Larissa respondeu que faz uso das "redes sociais como Facebook, Instagram, Snapchat, pois o próprio conceito de upcycling tem em si, um apelo sustentável e de vanguarda. Transformando o consumo em uma experiência de co-criação, que desperta o desejo dos consumidores e, ao mesmo tempo, força-os a buscar alternativas para as peças que ali estão, retalhos de vida e de história, para serem transformadas e assim, prolongarem seu ciclo, aproximandose dos preceitos da sustentabilidade. 


\section{CONSIDERAÇÕES FINAIS}

O crescimento dos impactos ambientais, está inter-relacionado às decisões tomadas nos estágios do ciclo de vida do produto. Sendo assim, torna-se ainda mais importante a preocupação com o futuro do planeta, com isso existem diversas alternativas de consumo consciente, como foi visto o upcycling é uma delas.

Nesse sentido, o artigo atendeu ao objetivo proposto, que foi o de investigar como a marca Recollection Lab, Criciúma, Santa Catarina, Brasil reutiliza peças descartadas, servindo como matéria-prima para o surgimento de um novo nicho no segmento da moda: o upcycling.

$O$ atelier, desenvolve peças customizadas e/ou transformadas com o objetivo de estimular a sustentabilidade, originalidade e exclusividade nas peças produzidas pela artista Larissa Moraes, proprietária da marca. Assim, com base na pesquisa bibliográfica e exploratória, foi possível compreender os conceitos básicos que envolvem o upcycling, o objetivo da marca estudada e a organização do trabalho, sob a ótica do upcycling. Por meio da entrevista foi possível identificar quais as referências, a designer utiliza como forma de inspiração no processo de customização e/ou transformação das peças, meios de divulgação, objetivo e posicionamento da marca quanto à forma de produção.

Foi possível observar que o upcycling têm seu valor, tendo como pressuposto a reutilização de produtos classificados como descartáveis; porém, quando transformados e/ou customizados, minimizam impactos negativos ao meio ambiente. Diferentemente do que acontece com o Recycling e o Downcycling, que exigem processos químicos. Com isso, estabelece-se um vínculo positivo entre a moda e a sustentabilidade tendo como principal aliado, o consumidor consciente, que reinventa a "moda", com peças únicas, exclusivas e, acima de tudo, com uma atitude mais próxima do que pode se considerar, ambientalmente correta! 


\title{
IMPORTANCE OF UPCYCLING IN FASHION DEVELOPMENT: MARKETING CASE STUDY ABOUT RECOLLECTION LAB BRAND
}

\begin{abstract}
:
The short life cycle of a fashion product has been a major environmental problem. From the raw material to the disposal of the items, several environmental impacts are generated; however, seeking a mitigation of these problems, some brands are bringing the concept of upcycling. Items that otherwise would have the trash as destiny are being relocate in the marketing chain and becoming the object of desire of many consumers. In this study, we focus on sustainability in fashion, as well as a brief case study on the Recollection Lab brand, and how reuse of discarded pieces served as a raw material for the emergence of a new niche in fashion that is: upcycling, what could give the product a new life.
\end{abstract}

Keywords: Fashion design. Sustainability. Upcycling. Consumption awareness.

\section{IMPORTANCIA DEL UPCYCLING EN EL DESARROLLO DE LA MODA: ESTUDIO DE CASO DE LA MARCA RECOLLECTION LAB}

\section{Resumen:}

El corto ciclo de vida de un producto de moda se ha demostrado que es un grave problema ambiental. Desde la materia prima hasta su eliminación, diversos impactos ambientales se generan y como una minimización de marcas alternativas vienen con el concepto de Upcycling. Lo que sería destinado a la basura, se convierte en producto de un nuevo atractivo y posicionamiento en el mercado. Este artículo tiene como objetivo investigar cómo la marca Recollection Lab., de Criciúma, Santa Catarina, Brasil vuelve a utilizar las piezas que teníam por fin su eliminación, que sirve como materia prima para la aparición de un nuevo nicho en el segmento de la moda, El Upcycling, dando una nueva vida al producto.

Palabras clave: Moda. Sostenibilidad. Upcycling. Consumo consciente. 


\section{REFERÊNCIAS}

AKTAS, R.; KAYALIDERE, K.; KARGIN, M. Corporate sustainability reporting and analysis of sustainability reports in Turkey. International Journal of Economics and Finance, v. 5, n. 3, p. 113-125, 2013.

ANICET, Anne. Colagens têxteis: em busca de um design sustentável. Tese de Doutorado em Design, Universidade de Aveiro. Aveiro, 2012.

AUS, R. Trash to Trend - Using Upcycling in Fashion Design. Tallinn: Estonian Academy of Arts, 2011.

BARTHES, R. Sistema da moda. São Paulo: Ed. Nacional; Ed. da Universidade de São Paulo, 1979.

BERLIM, Lilyan. Moda e Sustentabilidade: uma reflexão necessária. São Paulo: Estação das Letras e Cores, 2012.

BERLIM, Lilyan Guimarães. Transformações no campo da moda: crítica ética e estética.

BIANCHI, C.; BIRTWISTLE, G. SELL. Give away, or donate: an exploratory study of fashion clothing disposal behaviour in two countries. The International

Review of Retail, Distribution and Consumer Research, v. 20, n.3, p. 353-368, 2010.

BAUMANN, H.; BOONS, F.; BRAGD, A. Mapping the green product development field: engineering, policy and business perspectives. Journal of Cleaner Production, Amsterda, v.10, n.5, p.409-425, Oct. 2002.

BRAUNGART, Michael; MCDONOUGH, Willian. Cradle to cradle. Remaking the way we make things. London: Vintage Books, 2002.

CALDAS, Dário. Universo da Moda. 2017. Disponível em: <http://www.ameneguete.com.br/wp-content/uploads/2017/06/77841729-UniversoDa-Moda-Dario-Caldas.pdf> acessado em abril/2018.

CORNEO, G.; Jeanne, O. A theory of fashion based on segmented communication. Discussion Paper n. A-462, Department of Economics, University of Bonn, Bonn, 1994. 
ELKINGTON, J. Enter the triple bottom line. In: HENRIQUES, A.; RICHARDSON, J. (Ed.). The triple bottom line: does it all add up. London: EarthScan, 2004.

EPA - ENVIRONMENTAL PROTECTION AGENCY. Reuse, reduce \& recycle. Disponível em: <http://www.epa.gov/osw/> acessado em Fevereiro/2017.

FLETCHER, K.; GROOSE, L. Moda e sustentabilidade: design para mudança, Tradução Janaína Marcoantonio, São Paulo: Editora SENAC, 2011.

FUAD-LUKE, ALASTAIR. EcoDesign: The Sourcebook. São Francisco, CA: Chronicle Books, 2010.

GALLELI, B., SUTTER, M. B., MACLENNAN, M. L. F., POLO, E. F., \& CORREA, H. L. Sustentabilidade na moda brasileira: oportunidades e desafios no mercado internacional. Revista de Gestão Social e Ambiental, v. 9, n. 3, p. 45-62, 2016.

KRUCKEN, Lia. Design e Território-Valorização de identidades e produtos locais. Studio Nobel, 2009.

LJUNGBERG, L.Y. Materials selection and design for development of sustainable products. Materials and Desig. v.28, p.466-479, 2007.

MALAGUTI, C. Requisitos Ambientais para o desenvolvimento de produtos. São Paulo: CSPD - Centro São Paulo Design, 2005.

MANZINI, E. Design para a inovação social e sustentabilidade. Cadernos do Grupo de Altos Estudos, Programa de Engenharia de Produção da Coppe/UFRJ. Rio de Janeiro, vol. I, 2008.

BRAGA, Tania Moreira; MIKAILOVA, Irina; GUERRA, Cláudio Bueno; RAVSKI, Flavia Diniz. Grandes indústrias e impacto ambiental: análise empírica e métodos de mensuração aplicados às indústrias da Bacia do Piracicaba (MG). Belo Horizonte. Acessado Maio/2018.

MOREIRA, R. N., MARINHO, L. F. D. L., BARBOSA, F. L. S. O Modelo de Produção Sustentável Upcycling: o Caso da Empresa TerraCycle. ENGEMA, 2017. 
NILIPOUR, A.; NILIPOUR, A. Survey of the association between financial performance and corporate sustainability performance (Case Study: Cement Companies Accepted at Tehran Stock Exchange). Interdisciplinary Journal of Contemporary Research In Business, v. 3, n. 9, p. 10841092, 2001.

OLIVEIRA, J. A. C.; SPOSTO, R. M; BLUMENSCHEIN, R. N. Ferramenta para avaliação da sustentabilidade ambiental na fase de execução de edifícios no Distrito Federal. GEPROS. Gestão da Produção, Operações e Sistemas, v. 7, n. 2, p. 11-21, 2012.

RAUEN, F. J. Roteiros de Investigação Cientifica. Editora Unisul, Tubarão, 2002.

RECYCLING, UPCYCLING E DOWNCYCLING. Disponível em http://embalagemsustentavel.com.br/2011/02/17/recycling-downcyclingupcycling acessado em Fevereiro/2017.

ROZENFELD, H.; FORCELLINI, F.A.; AMARAL, D.C.; TOLEDO, J.A.; SILVA, S.L.; ALLIPRANDINI, D.H.; SCALICE, R.K. Gestão de desenvolvimento de produtos: uma referência para a melhoria do processo. São Paulo: Saraiva, 2006.

SAFFI, Beatriz. Brasília escala humana: upcycling com tecido descartado para a marca Pau-Brasília. 2015. 129 f., il. Monografia (Bacharelado em Desenho Industrial) — Universidade de Brasília, Brasília, 2015.

SAVITZ, A. W.; WEBER, K. A empresa sustentável: o verdadeiro sucesso é o lucro com responsabilidade social e ambiental. Rio de Janeiro: Campus, 2007.

SHOUP, K. RUBBISH! Reuse your Refuse. New Jersey: Wiley Publishing, 2008.

STRASSER, Susan. Waste and Want: A Social History of Trash. Studies in the Decorative Arts. Vol. 9, No. 2 (SPRING-SUMMER, 2002), p. 150-152.

VIEGAS, P. B.; BIANCHI, R. C.; MEDEIROS, F. S. B. Práticas sustentáveis ambientais utilizadas no setor de pós-vendas em concessionárias de veículos leves: um estudo de multicasos. GEPROS. Gestão da Produção, Operações e Sistemas, Bauru, Ano 10, no 1, jan-mar/2015, p. 101-117. 